\title{
Complementary and alternative medicinal approach to stress management
}

\author{
Tunna TS* \\ Assistant Professor, Department of Pharmacy, Primeasia University, Dhaka, Bangladesh
}

\begin{abstract}
Stress is an unavoidable part of our life experience and it is pertinent that we learn harmonious ways to balance our lives and protect ourselves from the many notoriety of it. In lieu to that complementary and alternative medicinal (CAM) approaches can be employed with their time approved methods and unconventional practices that are now having a comeback in recent years. Yoga, meditation, Herbal stress relief teas, Qigong, Energy Healing such as Chakra medication or healing and Reiki, Colour therapy all are branches of CAM that we can incorporate in our lives to soothe our souls and invigorate our mind. The following opinion paper touches the waters of a few of these CAM approaches as a guide to unlocking the potentials of these approaches.
\end{abstract}

Stress is a psychosomatic reaction of the mind and body to situations or triggers that an individual finds hard to deal with and it causes anxiety at the least. Stress over time leads to many physiological and psychological dysfunctions in the body [1]. Stress leads to a plethora of such effects as cardiovascular disease, respiratory issues, diabetes, allergy, miscarriage, anxiety and panic disorders, depression, low immune response etc. and is also a major cause of suicide in many backgrounds of people [2]. Suicide among Japanese workers is at an all-time high. It's high time the world takes note of this notorious daily life mate and tries to learn and develop ways to cope with this before it takes over our lives and reduces the quality of life.

Management of stress is a way of life than a single event. To successfully lead our best lives we need to consciously make effort to reduce our exposures and coping mechanism to stress. Life is stressful. There is no hiding or avoiding it. To be able to deal with stress successfully and effectively we need to learn about the effects and ways we can cope. We can choose one or more of the option and incorporate them in our lives as daily habits or rituals. Stress can be effectively managed by Yoga, meditation, mindfulness, healthy eating, exercise, acupressure, acupuncture, building relaxation rituals like massaging or drinking herbal teas such as rose, bamboo, chamomile, peppermint etc $[3,4]$.

van der Klink JJ, et al. [3] did a meta-analysis on the various aspects of stress reduction management techniques in the occupational sector. They distinguished their interventions as per medically viable options to be of four types, viz. the uses of relaxation techniques, cognitivebehavioural interventions, multimodal programs, and organizationfocused interventions. The study concluded that all the four types of intervention were effective but amongst them the cognitive-behavioural interventions were found to have the best stress managerial efficacy.

Daily rituals and routines such as waking up earlier and spending some time with nature, meditation, yoga and stretching will boost circulation, increase metabolism and will have a grounding effect to the individual. The starting of a day is so important. Therefore it is essential to set the tone of relaxation for the day which mentally prepares an individual to start off at a better start. The history of practicing yoga has been for thousands of years in Hindu and Buddhist sects in the Indian sub-continent. It is a combination of poses that work together with the breathing, physical movements therefore causing muscle toning and stretching along with deeper breathing which improves circulation, oxygenation and works as a relaxant in the long run [5]. Yoga has been found to be effective in treating various physiological and psychological ailments. Mental disorders are as depleting to ourselves as physical unwell.

Benefits of yoga lie in its core of employing mind and body to attain a state of balance. It has great stress busting capacity which makes it so effective in disorders like ADHD, Schizophrenia, anxiety disorders, panic attacks etc. A study by Vancampfort D, et al. [6] found the effect of just one session of aerobic exercise and yoga to reduce the stress effects of schizophrenic patients significantly. They found that yoga and exercise in general had three fold actions by working to decrease the anxiety state, reducing psychological stress and increased subjective wellbeing.

Let not wisdom scoff at strange notions or isolated facts. Let them be explored. For the strange notion are a new vision and the isolated fact a new clay, possible foundations of tomorrow's science [7]. On par the wise words of Edward F. Adolph, we need to open our eyes and consciousness to newer realms and delve deeper into territories that may sound eccentric to the least. Such an example in the alternative medicine realm is Energy Healing. This mode of therapy is well backed by science as according to laws of physics every matter is made of energy [8]. Simply put any and every matter has energy build into them

${ }^{\star}$ Correspondence to: Tasnuva Sarwar Tunna, Assistant Professor, Department of Pharmacy, Primeasia University, Dhaka, Bangladesh, E-mail: tasnuva tunna@yahoo.com

Key words: stress management, yoga, energy healing, chakra healing

Received: September 03, 2018; Accepted: September 14, 2018; Published: September 17, 2018 
Table 1. Summary of the main attributes of the seven chakras

\begin{tabular}{|c|c|c|c|c|}
\hline Chakra & Colour & Position & When open & When closed \\
\hline $\begin{array}{l}\text { Root } \\
\text { (Muladhara) }\end{array}$ & Red & $\begin{array}{l}\text { Base of the sacral } \\
\text { bones/ feet }\end{array}$ & $\begin{array}{l}\text { Gives a feeling of peace and accomplishment regarding } \\
\text { money, safety and shelter. }\end{array}$ & $\begin{array}{l}\text { Anxiety, disbalance, digestive issues, prostate and } \\
\text { ovarian issues }\end{array}$ \\
\hline $\begin{array}{l}\text { Sacral } \\
\text { (Svadhishana) }\end{array}$ & Orange & Right below the navel & $\begin{array}{l}\text { Relish in pleasurable activities, enjoying life, feeling } \\
\text { creative and abundant }\end{array}$ & $\begin{array}{l}\text { addiction, obesity, gluttony, hormone imbalances } \\
\text { and restlessness. }\end{array}$ \\
\hline Solar Plexus (Manipura) & Yellow & $\begin{array}{l}\text { Above the navel, right } \\
\text { below the sternum }\end{array}$ & $\begin{array}{l}\text { Personal power, confidence, wisdom, gut feeling. Sense } \\
\text { of self and sense of tackling life issues }\end{array}$ & $\begin{array}{l}\text { Quick to get angry, urge to control and } \\
\text { micromanage, greediness, lack of compassion or } \\
\text { empathy. }\end{array}$ \\
\hline Heart (Anahata) & Green & Right over the heart & $\begin{array}{l}\text { Feeling of love for oneself and others, compassion along } \\
\text { with health and healing. }\end{array}$ & $\begin{array}{l}\text { fast heart rate, palpitations, heart burn and issues } \\
\text { with interpersonal relationship }\end{array}$ \\
\hline Throat (Vishudho) & Blue & $\begin{array}{l}\text { Base of throat (between } \\
\text { collar bones) }\end{array}$ & $\begin{array}{l}\text { Speak clearly with love, kindness and truth, self- } \\
\text { expression and communication will be attained. }\end{array}$ & $\begin{array}{l}\text { Feeling unheard, not understood, speaking loudly, } \\
\text { interrupting others, oral and moth ulcers and } \\
\text { cavities, teeth issues. }\end{array}$ \\
\hline Third eye (Ajna) & Indigo & Middle of forehead & $\begin{array}{l}\text { Intuition, forecasting, opening the spiritual path to } \\
\text { self-exploration and self-development, tuning with the } \\
\text { material world and the spiritual realm }\end{array}$ & Allergy, sinus, headaches, not feeling balanced, \\
\hline Head (Sahaswara) & Purple & $\begin{array}{l}\text { Center of the top of } \\
\text { the head }\end{array}$ & $\begin{array}{l}\text { Pure consciousness, feeling taken care of by The Greater } \\
\text { power, feeling balanced, nurtured and supported. }\end{array}$ & $\begin{array}{l}\text { Depression, anxiety, suicidal issues, feeling of } \\
\text { chaos and disbalance }\end{array}$ \\
\hline
\end{tabular}

and they can be influenced by external and internal frequency. The atoms and molecules are vibrating in their places and their vibrational frequency can be altered by altering the energy around them. Similarly the energy inside a biological life is similar in nature to that of inorganic matter. The theory of energy healing states that human body has seven individual energy vortexes which in Sanskrit is called Chakras. Each of these has their individual colour and position. (Table 1) depicts some essentials on the chakras [9].

The realm of energy healing extends to the entire human existence and can be utilized to correct various disorders of the mind, heart and bodies. Reiki is another powerful world acclaimed energy healing technique. Energy healing has been proven to be effective against breast cancer, stress management, other forms of cancer, pain management along with general wellbeing of the practitioner [10].

These are some of the more unconventional and sometimes depicted as unorthodox healing techniques that are practiced the world over. The teachings of these thousand years old techniques may be frown upon but they are sure effective. Where medications and surgeries are failing the art of leading a life of balance and harmony through the clever use of meditation, yoga, nurturing the soul seems to making more leaps of improvements. There is a lacking in more synchronized and in-depth scientific researches regarding these topics and hopefully in future more researchers will be inclined to study them.

\section{References}

1. Iso H, Date C, Yamamoto A, Toyoshima H, Tanabe N (2002) Perceived mental stres and mortality from cardiovascular disease among Japanese men and women: the japan collaborative cohort study for evaluation of cancer risk sponsored by monbusho (JACC Study). Circulation 106: 1229-1236. [Crossref]

2. Scott SB, Graham-Engeland JE, Engeland CG, Smyth JM, Almeida DM, et al. (2015) The effects of stress on cognitive aging, physiology and emotion (ESCAPE) project. BMC psychiatry 15: 146. [Crossref]

3. van der Klink JJ, Blonk RW, Schene AH, van Dijk FJ (2001) The benefits of interventions for work-related stress. Am J Public Health 91: 270-276. [Crossref]

4. Chong CS, Tsunaka M, Tsang HW, Chan EP, Cheung WM (2011) Effects of yoga on stress management in healthy adults: a systematic review. Alternative therapies in health and medicine 17: 32. [Crossref]

5. Granath J, Ingvarsson S, von Thiele U, Lundberg U (2006) Stress management: a randomized study of cognitive behavioural therapy and yoga. Cognitive behaviour therapy 35: 3-10. [Crossref]

6. Vancampfort D, Vansteelandt K, Scheewe T, Probst M, Knapen J, et al. (2012) Yoga in schizophrenia: a systematic review of randomised controlled trials. Acta Psychiatrica Scandinavica 126: 12-20. [Crossref]

7. Fregly MJ, Fregly MS (1982) Edward F. Adolph. Physiologist 25: 1. [Crossref]

8. Penrose R (1991) The mass of the classical vacuum. The Philosophy of the Vacuum.

9. White DG (2003) Kiss of the yogini:" Tantric sex" in its South Asian contexts University of Chicago Press.

10. Subramani R, Lakshmanaswamy R (2017) Complementary and alternative medicine and breast cancer. In Progress in molecular biology and translational science. Academic Press 151: 231-274.

Copyright: (C)2018 Tunna TS. This is an open-access article distributed under the terms of the Creative Commons Attribution License, which permits unrestricted use, distribution, and reproduction in any medium, provided the original author and source are credited. 